\title{
Nativized Texts: Cultural Clues' Role in Improving EFL Undergraduates' Reading Comprehension
}

\author{
Asmahan Jameel Hattab Alali", Dina Abdul Hameed Al-Jamal, Imad Sa'di \\ Department of Curriculum and Methods of Instruction, Faculty of Education, Yarmouk University, Jordan
}

Received August 5, 2020; Revised August 31, 2020; Accepted October 19, 2020

\section{Cite This Paper in the following Citation Styles}

(a): [1] Asmahan Jameel Hattab Alali, Dina Abdul Hameed Al-Jamal, Imad Sa'di, "Nativized Texts: Cultural Clues' Role in Improving EFL Undergraduates' Reading Comprehension," Universal Journal of Educational Research, Vol. 8, No. 11, pp. 5555 - 5568, 2020. DOI: 10.13189/ujer.2020.081159.

(b): Asmahan Jameel Hattab Alali, Dina Abdul Hameed Al-Jamal, Imad Sa'di (2020). Nativized Texts: Cultural Clues' Role in Improving EFL Undergraduates' Reading Comprehension. Universal Journal of Educational Research, 8(11), 5555 - 5568. DOI: 10.13189/ujer.2020.081159.

Copyright $\odot 2020$ by authors, all rights reserved. Authors agree that this article remains permanently open access under the terms of the Creative Commons Attribution License 4.0 International License

\begin{abstract}
Even though many studies were carried out regarding the role of cultural background knowledge in reading comprehension, still rare studies were carried in the surrounding area. Accordingly, this study aimed at exploring the potential effect of cultural clues on $\mathrm{Al}$ alBayt University undergraduates' reading comprehension at three levels: literal, inferential, and evaluative. To achieve this, seven passages, each with two versions: the original and nativized, were selected from the textbook taught at $\mathrm{Al}$ al- Bayt University, situated in Mafraq in the north of Jordan. The researcher used pre-experimental design (i.e., One-group pretest-posttest design). In this design, a single case is observed at two-time points (repeated measures), one before the treatment (O1), and one after the treatment $(\mathrm{O} 2)$. Subjects were thirty-eight EFL undergraduates selected by the researcher from $\mathrm{Al}$ alBayt University in the second semester of the academic year 2019/2020. To carry out the study, all expressions and clues that carry cultural aspects in the original passages were replaced by other expressions reflecting the Jordanian culture in the nativized ones. The students then were asked to read the two versions and answer different types of questions to collect the data aimed at measuring literal, inferential, and evaluative comprehension over the two versions of each passage. The collected data were analyzed using quantitative analyses. The study's findings revealed that cultural familiarity through applying nativization positively affected students' reading comprehension. More interesting is that text nativization did affect the literal level of comprehension and the
\end{abstract}

inferential and evaluative ones. The current study would be fruitful for instructors and teachers in Jordan to help them develop reading comprehension in a way that would improve students' comprehension.

Keywords Reading Comprehension Levels, Schema Theory, Cultural Clues, Nativization, Al al- Bayt University

\section{Introduction}

Reading is a matter of comprehending a text rather than a mere act of decoding its phonemes. It is vital in developing any reader's vocabulary items, syntactic structures, and of course, cultural topics and themes. : Learners, in general, consider this skill as the one which opens the way for other skills, namely, writing, speaking, and listening, but still, as many readers face difficulties in understanding the meaning conveyed by the text.

When it comes to reading comprehension classes, the meaning is paramount and attained through embarking on the reader's schemata. Accordingly, in this age of globalization, considering learners' background knowledge in reading classes might lead to promising results where those learners achieve two aims: gaining the message of the reading text by recalling prior knowledge and being motivated since they are familiar with the topic of the reading text. 
In that way, reading has been described excessively in this regard. For example, Grabe and Stoller [1], introduced it as ".. the ability to draw meaning from the printed page and interpret this information appropriately" (p. 9). Ajideh [2] defined it as a reasoning activity in which the reader creates meaning based on available textual clues. Similarly, Cameron [3] highlighted the importance of comprehending the text and proceeded to label reading as a complex activity that is about meaning-making. Wolf [4] also regarded reading as "a neuronal and intellectually circuitous act, enriched as much by the unpredictable indirections of a direct message to the eye from the text" ( $\mathrm{p}$. 18).

Rose-Smith [5] added that reading comprehension is more than visual word identification; it involves reading beyond words. It means that the reader has to select the appropriate word meaning related to the reading text context. So the reader should comprehend what he reads by constructing a kind of relation between what he/she has in mind and what is being already read. Perfetti, Landi and Oakhill [6] stated that a reader should be able of creating a full understanding of the passage across sentences using skills in his/her memory, which means that comprehending a text is a kind of constructing a mental representation of what is presented in the reading text. In this regard, readers need more than reading the words and translating them. They need to use their experience, i.e., the reading process does not only about the memorization of words' meanings. Something else affects this process; it is the previous knowledge that the reader has in mind before. Moreover, we have to bear in mind that readers do not have the same prior knowledge in their minds. Accordingly, readers will have different analyses of the same reading passage. Each one will analyse and understand the text according to his/her previous knowledge. So readers' comprehension is positively affected by their prior knowledge or what is called schema.

It is claimed that language and culture cannot be separated, which means that they are connected firmly. Since culture plays a significant role in teaching reading as it is illustrated before, it is essential to focus on cultural background clues. On cultural clues, it was noticed by Rumelhart [7] the schema theory's emphasis that reading comprehension is an interactive process between the readers, previous background knowledge, and the text. As such, the cultural background is called back, while the reading process takes place.

Evidence on the role of background knowledge in reading comprehension was acknowledged by Anderson and Person [8], who noticed that the readers could only fully comprehend a text if they already know quite a bit about what is in the text. The role of background knowledge in developing reading comprehension was also discussed in a theoretical model known as Schema Theory by Carrell and Eister [9]. This theory shows that any text does not convey meaning in itself. Therefore, readers develop meaning by using their background knowledge as the interpretation of a given text is influenced by the reader's personal history, cultural background, and ideas.

Generally, Ketchum [10] stated that native readers possess the necessary cultural background when approaching a written text, while non-native readers must overcome an added challenge of cultural unfamiliarity when processing written communication. The relationship between cultural background cues and reading comprehension was further investigated by Kim [11], and thereby concluding that "a text by itself does not carry meaning, but instead guides readers in retrieving meaning based on their prior knowledge "(p. 36). Earlier, Garner [12] proposed Kim's same idea; he stated that readers construct meaning by directing their cognitive resources and considering prior knowledge relevant to the text.

One of the most exciting findings of schema-theoretic studies is the role of cultural background knowledge in reading comprehension conducted by Jalilifar and Assi [13]. This indicates that non-native readers may fail to activate appropriate cultural schemata, which leads to different degrees of non-comprehension. Nevertheless, native readers can activate the necessary cultural background knowledge while reading .

It was emphasized that background knowledge is vital for the inferential level of reading comprehension because this kind of knowledge provides the reader with information that is not conveyed by words in the text. We cannot here deny the importance of the literal level, because both the text and the information in it are essential. However, the reader and the knowledge he/she brings to the reading task are considered critical factors for reaching the complete meaning of the text. In the reading process, three models are used by readers: the bottom-up process, top-down process, and interaction between the two.

These three processes were discussed by Barnett [14], and she called them models of reading. She stated that in the bottom-up model, the reader creates comprehension by decoding letters, words, and sentences, so it is a text-driven model. She added that in the top-down model, the reader activates his/her schemata to construct comprehension, so it is called a schema-based model. Simultaneously, the interaction between the reader and the passage can be achieved in the third model.

The process of comprehension, as discussed before, can be driven by one of three previous models: top-down, bottom-up, and interactive. Nevertheless, how can the comprehension process be examined? This can be done by checking comprehension levels used by the reader. Clymer [15] discussed how Thomas Barrett developed a three-level taxonomy that shows how readers comprehend the text. Firstly, literal comprehension relies on the information explicitly presented in the text. Secondly, inferential comprehension relies on 
information that is not explicitly presented in the text. Inferential comprehension allows the reader to infer or guess by calling up his or her background knowledge. Barrett's third level is evaluative comprehension, in which the reader makes judgments about various aspects of the text. Although this level of comprehension relies on the text, the reader needs to make personal judgments about it. It is sometimes said that these personal judgments are also inferences like those in the inferential level, but they are dependent on the reader's background.

The main goal of reading is to comprehend the meaning conveyed by the writer. This comprehension cannot be achieved by vocabulary and structures contained in the text, because the writer of the text uses his/her schema which may not be enough for the reader to comprehend the message intended. Here also, the reader's schema has to be brought if it is related to new information in the passage.

Many scholars explained using background knowledge (schemata) while reading, and they discussed this use through what is called the schema theory. Jalilifar and Assi [13] propped that many scholars conducted studies that explained schema theory and its effects on comprehension in the reading process. Most notable was the focus on the cultural schema, which includes cultural aspects and their role in comprehending reading passages. Also, the lack of reaching the intended meaning of the text might be due to the inability to bring the appropriate cultural schema by non-native readers, and this will lead to misunderstanding.

Additionally, it is implied that a kind of interaction exists between the reader's schema and his own experience on the one hand and the strategies used to improve this schema on the other hand. Also, Nassaji [16] presented that schema brings the meaning of one's available knowledge structure, stored in mind. This means that the reader can actively engage his /her prior knowledge and reasoning skills to construct meaning. Davoudi and Ramezani [17] also presented a definition of the schema as the cluster of data containing general ideas stored in ones' mind. This means that the meaning conveyed by the text is not only what words or sentences have, but also the schema that the reader has in his mind. This leads us to the classification made by Bernhardt [18]; he stated that schemata are divided into two kinds: content and formal schema. The content schema represents the prior knowledge which the reader already has about the text content. While formal schema represents linguistic information that is significant for understanding the meaning or the message conveyed by the writer. Erten [19] added a third type, a cultural schema, and it is very connected to the current study. Erten claimed that the cultural schema is the umbrella under which content schemata exists because cultural schema includes bringing the needed knowledge to comprehend the message conveyed by the writer. This happens when the reader has the appropriate cultural belonging.

In this respect, it is essential to mention that culture is explained by Hinkle [20]from two different aspects: observable and unobservable aspects. Observable aspects such as traditions, customs, styles of dress, food, and festivals while unobservable aspects such as Socio-cultural standards, worldviews, beliefs, presumptions, and regard. These aspects may be referred to as cultural clues that are needed to help students comprehend the text's intended meaning. We can also construct a relationship between these aspects and prior knowledge since it is a significant aspect of a successful reading. Furthermore, Brantmeier [21] suggested that prior knowledge plays a vital role in reading comprehension, which means that when ESL students lack the cultural background knowledge, their comprehension of a passage will be negatively affected. Similarly, Pulido [22] investigated how cultural background knowledge affected reading comprehension and how it is considered to be very important in comprehending the message conveyed by the passage.

The previous observable and unobservable aspects of culture are always explained in terms of interplay in social settings, but teachers do not always try to nativize passages for successful educational purposes. Accordingly, they have to recognize cultural schema or cultural clues needed for text teaching, and to achieve the teaching goals, especially in teaching a text of a different culture, educators may get the use of cultural nativization of the intended text.

The concept of nativization supports the use of relevant schema in the text to improve understanding. Alptekin [23] introduces cultural nativization as "a sociological, semantic and pragmatic adaptation of the textual and contextual cues of the original story into the reader's own culture while keeping its linguistic and rhetorical content essentially intact" (p. 13). The process of nativization brings that information into the structure of language that is the product of schematic knowledge or background knowledge of the learner.

Jalilifar and Assi [13] advise that textual cues and contextual cues must be identified before starting the process of nativization. Accordingly, the researcher has to identify both of them in detail. Textual cues refer to locations, settings, and certain characters, e.g., names of persons like Ali and Ahmed and the names of the places as Lahore, Karachi, etc. On the other hand, according to Aleptkin [23], contextual cues represent culture-specific customs, rituals, notions, structures, and values. Contextual cues also include food, currency, clothes, drinks, and institutions. After identifying certain words, their equivalents in the local culture are included in the nativized materials. It was also ensured that linguistic features and rhetorical structures of the original materials remain the same.

As the idea of nativization calls for the use of related 
schema in the reading passage to achieve successful comprehension, many scholars focused on the significant role of schema in reading comprehension. Schema provides readers with the ability to comprehend the text easily. Therefore, a cultural schema is significant to comprehend the meaning related to the writer's message thoroughly. Ketchum [24] also discussed this kind of schema, and he emphasized that it is related to the content schema, which is also culture-specific. Moreover, if we go back, it is noticed that this kind of schema was defined by Oller [25] as it includes cultural familiarity, which enables readers to rebuild the text by activating some culturally relevant values. Thus, the cultural schema does not rely on literal comprehension of the passage; it moves to inferential comprehension.

Many scholars are interested in finding out the connection between prior knowledge and reading comprehension which thus resulted in, what Beck and McKeown [26] called, an "explosion of research" that has "greatly enhanced understanding of how one's background knowledge about text concepts functions in the reading process" ( p. 15).

In this respect, Johnson [27] tested how reading comprehension was affected by the cultural origin and linguistic complexity. To achieve the study's purpose, a group of American students who speak one language and another group of Iranian ESL students were chosen. Thus both groups were related to two different cultures, which reveals that each group has its cultural background. To conduct the study, each group was given two stories. The first group was given two English stories that are culturally unfamiliar, i.e. each story was related to different folklores: the first was connected with American folklore, whereas the other was connected with the Iranian one. The second group was asked to read the same stories in restructured English. Then both groups were given a test contained multiple-choice questions. It was shown that participants' comprehension was significantly affected by the story's cultural origin more than linguistic complexity. It is also shown that native English students' comprehension was affected by linguistic complexity and cultural origin.

Furthermore, Bedir [28] conducted an experiment that ensured that developing students' reading comprehension can be achieved by urging them to activate their background knowledge related to the reading text topic. To conduct the study, a quasi-experimental design was used by the researcher. Furthermore, for this purpose, the selected students were put into two groups: experimental and control groups. T.V, pictures, role-play, and games were used to train the former group, whereas traditional teaching was used for the latter group. The performance of the experimental group in the post-test was better than his performance in the pre-test. This result might be related to the use of cultural background, which thus mirrored on the successful performance of subjects who were trained with the cultural aspect. The results also revealed that successful reading comprehension was due to cultural schemata.

Related to the same field, Sasaki [29] focused on the significance of the schemata. He examined how cloze test-taking processes used for students who studied English as a foreign language were affected by familiar cultural aspects. For this purpose, sixty Japanese EFL students were selected and put into two groups bearing in mind their equivalence in English reading proficiency. To carry out the study, the participants were given two versions of a cloze test: one version was provided with culturally familiar aspects while the other version of the test was culturally unfamiliar. The participants were then demanded to produce verbal reports of the test processes, and when finishing the test, they were asked to recall what has been read. It was found that the participants who were asked to read the cloze passage provided with culturally familiar aspects performed better in comprehending the passage comparing to participants who were asked to read the original text.

Concerning schemata, Chang [30] investigated how background knowledge affected readers' reading comprehension. Accordingly, thirty low intermediate EFL students were chosen from Taiwan. The participants were classified into two groups who were demanded to read a text with the same level of familiarity and difficulty. While reading the text, the two groups were trained differently using different plans. The first group was taught using some cultural pre-reading activities to activate prior knowledge, whereas the second group was taught traditionally without such activities. After the reading process finished by the two groups, they were given a reading comprehension test. The study results showed that the group who was permitted to use cultural pre-reading activities had better scores than those who were not permitted to use such activities.

Besides, Garth-McCullough [31] checked out how reading comprehension is influenced by the cultural orientation of literature and background knowledge. To achieve his purpose, the researcher chose six stories connected to various cultures, each story related to different cultures, such as African American, Chinese American, and European American. The participants of this study were 117 eighth grade African American students. According to a test called ITBS, they were classified into three levels of readers: low readers, mid readers, and high readers. When starting to conduct the study, a background knowledge instrument was used to measure students' understanding of the story's cultural context. Then, the students started to read the six stories. Having finished reading each story, the students should answer some questions with two levels: literal and inferential. Completing this step, the students should answer a short post-survey where they should answer questions about their preferred level, text familiarity, and 
difficulty. It was found that students' comprehension was positively influenced by students' high level of cultural background knowledge of the African American stories despite their previous levels of achievement.

Besides, Dehghan and Sadighi [32] examined how students' performance on bottom-up and top-down reading processes could be influenced by cultural background. For this purpose, five culturally familiar themes and five culturally unfamiliar themes were used. In this study, three top-down processing items and three bottom-up processing items were used to evaluate the selected passages. The participants were 66 female pre-university learners aged 17 to 18 . It was shown that the participants bottom-up items were comprehended better than top-down ones. Also it was shown that cultural familiarity positively affected students' performance. Moreover, the study revealed that this difference in students' performances might be due to the verity in teaching methods and strategies where language teachers ignore using top-down processes in teaching reading comprehension.

Rashidi and Heidari [33] conducted a study about the influence of cultural background in Iran. They attempted to determine if using culturally-loaded texts in teaching EFL learners impacted their performance in reading comprehension tests. The participants were 102 Persian EFL learners who were put into two classes. The experimental class received treatment (teaching culture-loaded texts). Also, they were asked to answer a motivation questionnaire. The other class did not receive the same treatment. The findings showed that learners' performance on reading comprehension tests was influenced by teaching using cultural elements of the target language. It was also indicated that teaching cultural elements while practicing reading comprehension has a vital role in improving language learners' motivation.

Maghsoudi [34] attempted to determine if the schema activation affects reading comprehension of culturally-loaded passages. The study sample contained 76 students who were classified into two groups: control and experimental. Pre-reading activities were used to teach the participants in the experimental group to help them activate their prior knowledge, whereas the control group was taught traditionally. The study's results revealed a remarkable difference between pre-tests' mean scores and post-tests in the case of the experimental group before activating prior knowledge and after doing that. Also, it was emphasized that students who activated more background knowledge related to the text topic developed their cultural passages' comprehension.

Additionally, Yousef, Karimi, and Janfeshan [35] investigated the influence of cultural schema on reading comprehension. To achieve the study's purpose, 45 language learners majoring in TEFL and English language translation were selected from universities in
Iran. The learners were related to three various ethnicities. In order to collect the data, the participants were given three various reading comprehension sub-tests. The first reading sub-test contained culturally familiar themes, and the other two reading sub-tests contained culturally unfamiliar themes. The results indicated that the students' performance in reading the familiar themes was better than their performance in reading unfamiliar themes.

To improve students' language proficiency, Khataee and Davoudi [36] examined the impact of schema on reading comprehension. The sample was taken from Hakim Sabzevari University, containing 67 students majoring in the English language who were classified into two groups: experimental and control. Participants in the control group were taught traditionally without treatment, whereas participants in the experimental group were provided with background knowledge. The results revealed that when students were provided by cultural background related to the topic they are reading, this would positively influence their inferential reading comprehension and accordingly improve their language proficiency.

To examine the influence of cultural familiarity in EFL education in Japan, Sheridan, Tanaka, and Hogg [37] carried out their study. To conduct this study, both qualitative and quantitative methods were considered with a sample included 78 intermediate level EFL students who were taken from four classes. The students were classified into two groups, and they were provided with four simplified articles taken from the newspaper. These articles included nouns which are either culturally familiar or unfamiliar. To discover the influence of cultural familiarity on readers' comprehension, two tests were adopted: pre- and post-tests. The study's results revealed that students who were given the articles containing culturally familiar proper nouns performed better than other students who were given the articles that contained culturally unfamiliar proper nouns.

Related to the current study, Razi [38] tested how reading comprehension was affected by both different reading activities and nativization. To carry out the study, he selected seventy-two students from the English department at Turkish University. To conduct the study, the researcher nativized a short story related to the American culture by rewriting it as if it took place in a Turkish city. Thus, all the American names of places and persons were replaced by Turkish names. Furthermore, American cultural clues such as clothes, religion, hobbies, and jobs were replaced by Turkish cultural ones. This study's design was a $2 \mathrm{X} 2$ quasi-experimental one, and the participants were classified into four groups. The first group read the original version of the American short story; the second group read the nativized version of the same story; the third group read the original short story provided by some reading activities. Finally, the fourth group read the nativized version provided by the same 
activities. It was found that the four groups have apparent differences in comprehending the same story. It was also found that the group who read the nativized version of the short story with reading activities had the best performance than the group who read the original story with reading activities. Later came the group who was read the nativized story without activities, and later was the group who read the original short story without reading activities. Accordingly, the researcher concluded that reading activities are vital as well as cultural nativization, which proved that nativizing the text is not enough for activating readers' cultural schemata, it should be provided with reading activities. These findings assured Alptekin's [23] conclusion and added that the lack of cultural schemata could be compensated by reading activities.

Concerning the concept of the effect of nativization on reading comprehension, Alptekin [23], Jalilifar, and Assi [13] carried out their study in which they explained the process of nativization. They attempted to investigate how readers' comprehension can be affected by nativization. For this aim, 29 male and 31 students were chosen. Accordingly, three American short stories were nativized to Persian culture. The first story includes 1100 words with six literal and six inferential questions. The second story contains 1500 words with eight literal questions and six inferential ones. Finally, the third story includes 1800 words with nine literal questions and six inferential ones. The participants were tested using multiple-choice questions. The study's results showed that both literal and inferential levels of comprehension were positively affected by cultural nativization.

Besides, Demir [39] examined how the nativization process influenced reading comprehension and vocabulary inferences. Accordingly, two passages were selected: the authentic version and nativized one. One hundred and twenty learners were selected from a Turkish primary school, and they were classified into experimental and control groups. The researcher developed a vocabulary test and parallel reading comprehension tests. The study's results showed that students' abilities to comprehend the text were developed when using cultural text nativization. Moreover, the students who read the nativized version of the text would perform better in reading comprehension tests and vocabulary tests than the students are given the original version.

It is noticed that previous studies suffered from some limitations. Firstly, aside from Garth-McCullough [31], with six selected stories, most researchers used a low number of stories or passages in conducting their studies. If we exclude Alptekin's [23] study, which investigated the effect of nativization on literal and inferential levels of comprehension, the previous studies focused on finding out the effect of cultural familiarity and text nativization on reading comprehension as a whole.

Another critical point is that the previous studies classified the participants into two or three groups, while in this study, the researcher did not classify the participants since the whole sample was given first the original versions of the reading passages then was given the nativized ones.

For the previous reasons and others this study is an attempt to explore the potential effect of cultural clues on EFL undergraduates' reading comprehension More specifically, the purpose of this study is to find out which level of comprehension, literal, inferential, or evaluative, nativization is mostly useful in reading comprehension. In summary, this study aimed to answer the following questions:

Q1: To what extent do cultural clues, embedded in original reading passages test, affect EFL undergraduate students' literal, inferential, and evaluative comprehension levels?

Q2: To what extent do cultural clues, embedded in nativized reading passages test, affect EFL undergraduate students' literal, inferential, and evaluative comprehension levels?

Q3: Are there any statistically significant differences between the test scores of the original and the nativized reading passages?

\section{Method}

Pre-experimental research (i.e., One-group pretest-posttest design) was employed. In this design, a single case is observed at two-time points (repeated measures), one before the treatment $\left(\mathrm{O}_{1}\right)$, and one after the treatment $\left(\mathrm{O}_{2}\right)$. Changes in the outcome of interest (dependent variable) are assumed to be the results of the treatment or intervention (X). No control or experimental group is employed. This design can be expressed in the following form: $\mathrm{O}_{1} \mathrm{X} \mathrm{O}_{2}$. In the present study, nativized reading passages are the independent variable, whereas, using cultural clues in EFL reading comprehension (students' performance: reading levels) is a dependent variable.

\subsection{Participants}

The participants of this study are 38 university students purposefully selected from Al al-Bayt University since the researcher works there. The participants are young adults (aged 19-23); they have studied English as an obligatory course. All students read original passages selected by the researcher from their textbook, and then they were asked to read nativized versions (by the researcher) of the same passages.

\subsection{Material}

The textbook used in the current study is Intermediate Students' book New Headway Plus. The Oxford University 
Press published it, and it is connected to its authors Liz and John Soars, who become leaders in designing curricula related to English language teaching and learning. It contains 12 units, and since more than one unit discusses some related topics, the researcher selected the units that cover different topics related to the current study and topics covered during each semester.

\subsection{Instrument}

To collect data needed for this study, the reading comprehension -test was developed to measure EFL undergraduates' performance in reading comprehension with its three levels: literal, inferential, and evaluative. This was used as a test covering seven reading passages taken from the textbook, which is taught for English 099 students at $\mathrm{Al}$ al-bayt University. This test was designed by the researcher to explore the effect of cultural clues on reading comprehension. The researcher selected seven passages containing cultural clues, such as customs, traditions, celebrations, and cultural practices. This test was divided into two parts: the first part was pre-test covering the original reading passages, while the second part was post-test covering the nativized reading passages. The pre-test contained 60 questions classified as 20 literal questions, 20 inferential questions, and 20 evaluative questions. The total number of the score was 60 . Similarly, the post-test contained 60 questions classified as the following: 20 literal questions, 20 inferential questions, and 20 evaluative questions.

Table 1. Results of Content Analysis (Table of Specification)

\begin{tabular}{|c|c|c|c|c|c|c|}
\hline Unit & Reading Level & Frequency & $\%$ & Reading sub-skills & Frequency & $\%$ \\
\hline \multirow{10}{*}{$\begin{array}{l}\text { Unit one } \\
\text { Getting to } \\
\text { Know You }\end{array}$} & \multirow{2}{*}{-Literal level } & \multirow{2}{*}{2} & \multirow{2}{*}{3} & -identifying important points & 1 & 2 \\
\hline & & & & -identifying the meaning of words & 1 & 2 \\
\hline & \multirow{5}{*}{-Inferential level } & \multirow{5}{*}{3} & \multirow{5}{*}{5} & -interpreting important points & 1 & 2 \\
\hline & & & & - gap-filling & 1 & 2 \\
\hline & & & & - referring pronouns & 1 & 2 \\
\hline & & & & - checking true/false statements & - & - \\
\hline & & & & -offering opinion & 1 & 2 \\
\hline & \multirow{3}{*}{-Evaluative level } & \multirow{3}{*}{1} & \multirow{3}{*}{2} & -analyzing information & - & - \\
\hline & & & & -evaluating & - & - \\
\hline & & & & -making a conclusion & - & - \\
\hline \multirow{10}{*}{$\begin{array}{l}\text { Unit two } \\
\text { The Way We } \\
\text { Live }\end{array}$} & \multirow{3}{*}{-Literal level } & \multirow{3}{*}{3} & \multirow{3}{*}{5} & -identifying important points & 2 & 3 \\
\hline & & & & -identifying the meaning of words & 1 & 2 \\
\hline & & & & -interpreting important points & 1 & 2 \\
\hline & \multirow{4}{*}{-Inferential level } & \multirow{4}{*}{4} & \multirow{4}{*}{7} & - gap-filling & - & - \\
\hline & & & & - referring pronouns & 2 & 3 \\
\hline & & & & - checking true/false statements & 1 & 2 \\
\hline & & & & -offering opinion & 1 & 2 \\
\hline & \multirow{3}{*}{-Evaluative level } & \multirow{3}{*}{4} & \multirow{3}{*}{7} & -analyzing information & 1 & 2 \\
\hline & & & & -evaluating & 1 & 2 \\
\hline & & & & -making a conclusion & 1 & 2 \\
\hline \multirow{10}{*}{$\begin{array}{l}\text { Unit three } \\
\begin{array}{l}\text { It all went } \\
\text { wrong }\end{array}\end{array}$} & \multirow{3}{*}{-Literal level } & \multirow{3}{*}{8} & \multirow{3}{*}{13} & -identifying important points & 1 & 2 \\
\hline & & & & -identifying the meaning of words & 7 & 12 \\
\hline & & & & -interpreting important points & 1 & 2 \\
\hline & \multirow{4}{*}{-Inferential level } & 8 & 13 & - gap-filling & 1 & 2 \\
\hline & & 8 & 13 & - referring pronouns & 4 & 7 \\
\hline & & & & - checking true/false statements & 2 & 3 \\
\hline & & & & -offering opinion & 3 & 5 \\
\hline & -Evaluative level & 9 & 15 & -analyzing information & 2 & 3 \\
\hline & -Evaluative level & 9 & 15 & -evaluating & 2 & 3 \\
\hline & & & & -making a conclusion & 2 & 3 \\
\hline & & & & -identifying important points & 6 & 10 \\
\hline & -Literal level & 7 & 12 & -identifying the meaning of words & 1 & 2 \\
\hline & & & & -interpreting important points & 1 & 2 \\
\hline & Inferentiol leye & 5 & 8 & - gap-filling & - & - \\
\hline Unit four & -Interential level & 5 & 8 & - referring pronouns & 2 & 3 \\
\hline Let us go & & & & - checking true/false statements & 2 & 3 \\
\hline snopping & & & & -offering opinion & 3 & 5 \\
\hline & Fyaluative leyel & 6 & 10 & -analyzing information & 1 & 2 \\
\hline & -Evaluative level & 6 & 10 & -evaluating & - & - \\
\hline & & & & -making a conclusion & 2 & 3 \\
\hline Total & & 60 & 100 & & 60 & \\
\hline
\end{tabular}




\subsection{Face Validity}

To establish the face and content validity of the instrument (the two tests), the measures were examined by a panel of experts from ten university professors and one English language supervisor. The experts' review was intended to evaluate the appropriateness of the content, wording, and the level of the language of the passages and their questions based on the purpose of the instrument. Accordingly, some modifications in the two tests have been conducted. Furthermore, the content validity of the tests was established by conducting the textbook's content analysis utilizing Table (1)

\subsection{Reliability}

Reliability of the original and nativized reading passages tests have been evaluated using the Cronbach Alpha approach. Table (2) shows Cronbach Alpha Coefficients for each reading level of the original and nativized reading passages tests and for the whole tests.

Table 2. Cronbach Alpha Coefficients for each reading level of the original and nativized reading passages tests and the whole tests.

\begin{tabular}{ccc}
\hline \multirow{2}{*}{ Reading level } & \multicolumn{2}{c}{ Cronbach Alpha Coefficients } \\
\cline { 2 - 3 } & Original & Nativized \\
\hline Literal & .76 & .86 \\
Inferential & .96 & .79 \\
Evaluation & .96 & .86 \\
Total & .94 & .92 \\
\hline
\end{tabular}

As we can see in Table (2), the Cronbach alpha coefficients for the literal, inferential, and evaluation reading levels of original reading passages test were $.76, .96$, and .96 , respectively, and it was calculated to be .94 for the entire scale, and all above the cut-off value (.70) (Cronbach, [40]). Furthermore, the Cronbach alpha coefficients for the literal, inferential, and evaluation reading levels of nativized reading passages test were $.86, .97$, and .86 , respectively, and it was calculated to be .92 for the entire scale, and all above the cut-off value (.70) (Cronbach, [40]).

\subsection{Procedure}

Nativization process

The passages selected for the current study were nativized into the Jordanian culture. To fulfill this, first, the textual and contextual clues of the original passages related to American culture were found out, and then these clues were adapted in the nativized versions to reflect Jordanian culture, without changing the linguistic features of the original passages. Accordingly, the result was having two versions of each passage: the original one as it was taken from the textbook, and the adapted (nativized) one, which included the modified cultural textual and contextual clues. Textual clues include characters, settings, and occupation, see Table (3), while contextual clues include customs, values, rituals, drinks, and currency, see Table (4).

Table 3. Examples of cultural textual clues taken from the passages

\begin{tabular}{|c|c|c|}
\hline $\begin{array}{c}\text { Type of Cultural } \\
\text { textual clues }\end{array}$ & $\begin{array}{c}\text { Example from } \\
\text { original version }\end{array}$ & $\begin{array}{c}\text { Example from } \\
\text { nativized version }\end{array}$ \\
\hline Countries & Bologna & Irbid \\
\hline Characters & Celi & Omar \\
\hline Locations & $\begin{array}{c}\text { University of } \\
\text { Bologna }\end{array}$ & $\begin{array}{c}\text { Yarmouk } \\
\text { University }\end{array}$ \\
\hline Streets & Champs-Elysees & Gardens street \\
\hline
\end{tabular}

Table 4. Examples of cultural contextual clues taken from the passages

\begin{tabular}{|c|c|c|}
\hline $\begin{array}{c}\text { Type of Cultural } \\
\text { contextual clues }\end{array}$ & $\begin{array}{c}\text { Example from } \\
\text { original version }\end{array}$ & $\begin{array}{c}\text { Example from } \\
\text { nativized version }\end{array}$ \\
\hline Food/sweets & Sohan/ Pizza & Mansaf/ Harisa \\
\hline Clothing & Dress & Dishdasha \\
\hline Currency & $100 \$$ & JD100 \\
\hline Nationality & Thai & Jordanian \\
\hline
\end{tabular}

\section{Results}

To answer the first question, the means and standard deviations of student's performance in original reading passages for the three levels of reading (i.e., Literal, Inferential, and evaluation) and their sub-skills were extracted. Table (5) illustrates the means and standard deviations of the three levels of original reading passages.

Table 5. Means and Standard Deviation of the three levels of Original reading Passages and their Sub skills

\begin{tabular}{cccc}
\hline Reading Level & Sub-skills & Mean & Std. Deviation \\
\hline \multirow{3}{*}{ Literal } & Identifying important points & 8.526 & .557 \\
& Identifying the meaning of words & 8.158 & .679 \\
& Total & 16.684 & .989 \\
\hline \multirow{3}{*}{ Inferential } & Interpreting important points & 3.579 & .793 \\
& Gap-filling & 3.500 & .797 \\
& Referring pronouns & 3.105 & .981 \\
& Checking true/false statements & 2.921 & .882 \\
Evaluation & Total & 13.105 & 3.278 \\
& Offering opinion & 3.158 & .855 \\
& Analyzing Information & 2.790 & .991 \\
& Evaluating & 2.500 & 1.007 \\
\hline Total Score & Making a conclusion & 2.395 & .974 \\
\hline
\end{tabular}

*The maximum score for each reading level is 20 ; the maximum score for each literal sub-skill is 10 , and the maximum score for each sub-skill for inferential and evaluation level is 5 . 
It is clear from Table (5) that the means of reading levels are $16.648,13.105$, and 10.842 , for literal, inferential, and evaluation, respectively. As such, the highest mean score was for literal reading level $(\mathrm{Mean}=16.648 ; \mathrm{Std}=.989)$, whereas, the lowest mean score was for evaluation reading level (Mean=10.842; $\mathrm{Std}=3.628$ ).

For literal reading level, the highest mean score was for "Identifying important points" sub-skill (Mean $=8.526$; $\mathrm{Std}=.557)$. For inferential reading level, the highest mean score was for "Interpreting important points) (Mean=3.579; $\mathrm{Std}=.793$ ), followed by "Gap-filling" (Mean= 3.500; $\mathrm{Std}=.797)$, whereas, the lowest mean score was for "Checking true/false statements" $\quad($ Mean $=\quad 2.921$; $\mathrm{Std}=.882$ ).

For evaluation reading level, the highest mean score was for "Offering opinion" sub-skill (Mean $=3.158$; $\mathrm{Std}=.855$ ), followed by "Analyzing Information" (Mean= 2.790; $\mathrm{Std}=.991)$, whereas, the lowest mean score was for "Making conclusion" (Mean= 2.395; $\mathrm{Std}=.974)$.

To answer the second question, the means and standard deviations of student's performance in nativized reading passages for the three levels of reading (i.e., Literal, Inferential, and evaluation) and their sub-skills were extracted. Table (6) illustrates the means and standard deviations of the three levels of nativized reading passages.
It is clear from Table (6) that the means of reading levels are: $18.658,17.211$, and 15.526 , for literal, inferential, and evaluation, respectively. As such, the highest mean score was for literal reading level (Mean= 18.658; $\mathrm{Std}=.1 .300$ ), whereas, the lowest mean score was for evaluation reading level (Mean=15.529. Std=2.227).

For literal reading level, the highest mean score was for "Identifying important points" sub-skill (Mean = 9.526; $\mathrm{Std}=.603$ ). For inferential reading level, the highest mean score was for "Gap-filling" (Mean= 4.395; Std= 547), followed by "Referring pronouns" (Mean= 4.342; $\mathrm{Std}=.627)$, whereas, the lowest mean score was for "Interpreting important points" (Mean $=4.211 ; \mathrm{Std}=.835)$.

For evaluation reading level, the highest mean score was for "Offering opinion" sub-skill (Mean = 4.026; $\mathrm{Std}=.434$ ), followed by "Analyzing Information" (Mean= 4.000; $\mathrm{Std}=.569)$, whereas, the lowest mean score was for "Making conclusion" (Mean= 3.711; $\mathrm{Std}=.835)$.

To answer the third question, it was observed that there are noticeable differences between the test scores of the original and the nativized reading passages. In other words, the mean scores of nativized reading passages and their sub-skills are higher than the mean scores of the original reading passages and sub-skills (see Table 5 and Table 6).

Table 6. Means and Standard Deviation of the three levels of reading Nativized Passages and their Sub skills.

\begin{tabular}{cccc}
\hline Reading Level & Sub-skills & Mean & Std. Deviation \\
\hline \multirow{2}{*}{ Literal } & Identifying important points & 9.526 & .603 \\
& Identifying the meaning of words & 9.132 & .777 \\
& Total & 18.658 & .300 \\
& Interpreting important points & 4.211 & .474 \\
Inferential & Gap-filling & 4.395 & .547 \\
& Referring pronouns & 4.342 & .627 \\
& Checking true/false statements & 4.263 & .644 \\
& Total & 17.211 & .473 \\
\hline Evaluation & Offering opinion & 4.026 & .569 \\
& analyzing Information & 4.000 & .741 \\
& Evaluating & 3.790 & .835 \\
\hline Total Score & Making a conclusion & 3.711 & 2.227 \\
\hline
\end{tabular}

*The maximum score for each reading level is 20 ; the maximum score for each literal sub-skill is 10 , and the maximum score for each sub-skill for inferential and evaluation level is 5 . 
To investigate the significance of the performance differences between students' performance in original and the nativized reading passages for the literal reading level and its sub-skills, Repeated Measures Analysis (i.e., Paired Samples t-test) were conducted. Table (7) illustrates the results of a paired samples t-test for the difference between student's performance in the original and the nativized reading passages for the literal reading level and its Sub-skills.

As shown in table (7), the results indicated that the mean score of the literal reading level of nativized reading passages (Mean $=18.658, \mathrm{Std}=1.300$ ) was significantly higher than the mean score of the literal reading level of original reading passages (Mean=16.648, $\mathrm{Std}=.989)$; $\mathrm{t}(37)$ $=8.663, \mathrm{p}<.01$; the standardized effect size index, $\mathrm{d}$, was 1.42 (enormous effect size: Cohen [41]).

For identifying important point's literal sub-skill, the results indicated that the mean score of nativized reading passages (Mean $=9.526, \mathrm{Std}=.603$ ) was significantly higher than the mean score of original reading passages $($ Mean=8.526, Std=.557); t $(37)=9.374, \mathrm{p}<.01$; the standardized effect size index, d, was 1.54 (considerable effect size: (Cohen [41]).
For identifying the meaning of words literal sub-skill, the results indicated that the mean score of nativized reading passages (Mean $=9.132, \quad \mathrm{Std}=.777$ ) was significantly higher than the mean score of original reading passages $($ Mean=8.158, Std=.679); $\mathrm{t}(37)=9.374, \mathrm{p}<.01$; the standardized effect size index, d, was 1.01 (considerable effect size: (Cohen, [41])

To investigate the significance of the performance differences between students' performance in original and the nativized reading passages for the inferential reading level and its sub-skills, Repeated Measures Analysis (i.e., Paired Samples t-test) were conducted. Table (8) illustrates the results of a paired samples t-test for the difference between student's performance in original and the nativized reading passages for the inferential reading level and its Sub-skills.

As shown in table (8), the results indicated that the mean score of the inferential reading level of nativized reading passages (Mean $=17.211, \mathrm{Std}=1.773$ ) was significantly higher than the mean score of the inferential reading level of original reading passages (Mean=13.105, $\mathrm{Std}=3,278$ ); $\mathrm{t}$ $(37)=13.420, p<.01$; the standardized effect size index, $d$, was 2.20 (enormous effect size: (Cohen, [41]).

Table 7. Results of a Paired samples t-test for the Difference between Student's Performance in Original and the Nativized Reading Passages for the Literal Reading Level and its Sub-skills.

\begin{tabular}{|c|c|c|c|c|c|c|c|}
\hline Sub-skills & & Mean & Std Deviation & T-values & Df & Sig. & $\begin{array}{l}\text { effect } \\
\text { size }\end{array}$ \\
\hline \multirow{2}{*}{$\begin{array}{l}\text { Identifying important } \\
\text { points }\end{array}$} & Original & 8.526 & .557 & \multirow{2}{*}{9.374} & \multirow{2}{*}{37} & \multirow{2}{*}{.000} & \multirow[t]{2}{*}{1.54} \\
\hline & Nativized & 9.526 & .603 & & & & \\
\hline \multirow{2}{*}{$\begin{array}{l}\text { Identifying the } \\
\text { meaning of words }\end{array}$} & Original & 8.158 & .679 & \multirow{2}{*}{6.174} & \multirow{2}{*}{37} & \multirow{2}{*}{.000} & \multirow[t]{2}{*}{1.01} \\
\hline & Nativized & 9.132 & .777 & & & & \\
\hline \multirow{2}{*}{ Total } & Original & 16.684 & .989 & \multirow{2}{*}{8.663} & \multirow{2}{*}{37} & \multirow{2}{*}{.000} & \multirow[t]{2}{*}{1.42} \\
\hline & Nativized & 18.658 & 1.300 & & & & \\
\hline
\end{tabular}

Table 8. Results of A paired samples t-test for the Difference between Student's Performance in Original and the Nativized Reading Passages for the Inferential Reading Level and its Sub-skills.

\begin{tabular}{|c|c|c|c|c|c|c|c|}
\hline Sub-skills & & Mean & Std Deviation & T- values & Df & Sig. & $\begin{array}{c}\text { Effect } \\
\text { size }\end{array}$ \\
\hline \multirow{2}{*}{ Interpreting important points } & Original & 3.579 & .793 & \multirow{2}{*}{6.608} & \multirow{2}{*}{37} & \multirow{2}{*}{.000} & \multirow[t]{2}{*}{1.09} \\
\hline & Nativized & 4.211 & .474 & & & & \\
\hline \multirow{2}{*}{ Gap-filling } & Original & 3.500 & .797 & \multirow{2}{*}{10.840} & \multirow{2}{*}{37} & \multirow{2}{*}{.000} & \multirow[t]{2}{*}{1.78} \\
\hline & Nativized & 4.395 & .547 & & & & \\
\hline \multirow{2}{*}{ Referring pronouns } & Original & 3.105 & .981 & \multirow{2}{*}{12.027} & \multirow{2}{*}{37} & \multirow{2}{*}{.000} & \multirow[t]{2}{*}{1.98} \\
\hline & Nativized & 4.342 & .627 & & & & \\
\hline \multirow{2}{*}{$\begin{array}{l}\text { Checking true/false } \\
\text { statements }\end{array}$} & Original & 2.921 & .882 & \multirow{2}{*}{10.156} & \multirow{2}{*}{37} & \multirow{2}{*}{.000} & \multirow[t]{2}{*}{1.67} \\
\hline & Nativized & 4.263 & .644 & & & & \\
\hline \multirow{2}{*}{ Total } & Original & 13.105 & 3.278 & \multirow{2}{*}{13.420} & \multirow{2}{*}{37} & \multirow{2}{*}{.000} & \multirow[t]{2}{*}{2.20} \\
\hline & Nativized & 17.211 & 1.773 & & & & \\
\hline
\end{tabular}


For interpreting important point's inferential sub-skill, the results indicated that the mean score of nativized reading passages (Mean $=4.211, \quad \mathrm{Std}=.474$ ) was significantly higher than the mean score of original reading passages (Mean=3.579, $\mathrm{Std}=.793)$; $\mathrm{t}(37)=6.608, \mathrm{p}<.01$; the standardized effect size index, $d$, was 1.09 (immense effect size: (Cohen, [41]).

For gap-filling inferential sub-skill, the results indicated that the mean score of nativized reading passages (Mean $=4.395, \mathrm{Std}=.547)$ was significantly higher than the mean score of original reading passages (Mean $=3.500, \mathrm{Std}=.797$ ); $\mathrm{t}(37)=10.840, \mathrm{p}<.01$; the standardized effect size index, $\mathrm{d}$, was 1.78 (enormous effect size: (Cohen, [41]).

For referring pronouns inferential sub-skill, the results indicated that the mean score of nativized reading passages (Mean $=4.342, \mathrm{Std}=.627$ ) was significantly higher than the mean score of original reading passages (Mean $=3.105$, $\mathrm{Std}=.981) ; \mathrm{t}(37)=12.027, \mathrm{p}<.01$; the standardized effect size index, d, was 1.98 (considerable effect size: (Cohen[41]).

For checking true/false statements inferential sub-skill, the results indicated that the mean score of nativized reading passages (Mean $=4.263, \quad \mathrm{Std}=.882$ ) was significantly higher than the mean score of original reading passages (Mean=2.921, $\mathrm{Std}=.644)$; $\mathrm{t}(37)=10.156, \mathrm{p}<.01$; the standardized effect size index, d, was 1.67 (considerable effect size: (Cohen [41]).

To investigate the significance of the performance differences between students' performance in original and the nativized reading passages for the evaluation reading level and its sub-skills, Repeated Measures Analysis (i.e., Paired Samples t-test) were conducted. Table (9) illustrates the results of a paired samples t-test for the difference between student's performance in original and the nativized reading passages for the evaluation reading level and its Sub-skills.

As shown in table (9), the results indicated that the mean score of evaluation reading level of nativized reading passages (Mean $=15.526, \mathrm{Std}=2.227$ ) was significantly higher than the mean score of the inferential reading level of original reading passages (Mean=10.842, $\mathrm{Std}=3.628$ ); $\mathrm{t}$ $(37)=16.435, p<.01$; the standardized effect size index, $d$, was 2.70 (considerable effect size: (Cohen [41]).

For offering opinion evaluation sub-skill, the results indicated that the mean score of nativized reading passages (Mean $=4.026, \mathrm{Std}=.434$ ) was significantly higher than the mean score of original reading passages (Mean $=3.158$, $\mathrm{Std}=. .855) ; \mathrm{t}(37)=8.055, \mathrm{p}<.01$; the standardized effect size index, d, was 1.32 (considerable effect size: (Cohen [41]).

For analyzing Information evaluation sub-skill, the results indicated that the mean score of nativized reading passages (Mean $=4.000, \mathrm{Std}=.569$ ) was significantly higher than the mean score of original reading passages $($ Mean=2.790, Std=.797); $\mathrm{t}(37)=11.273, \mathrm{p}<.01$; the standardized effect size index, d, was 1.85 (enormous effect size: (Cohen [41]).

For evaluating evaluation sub-skill, the results indicated that the mean score of natvized reading passages (Mean $=3.790, \mathrm{Std}=.741)$ was significantly greater than the mean score of original reading passages (Mean $=2.500$, $\mathrm{Std}=.1 .007) ; \mathrm{t}(37)=13.008, \mathrm{p}<.01$; the standardized effect size index, d, was 2.15 (very large effect size: (Cohen [41]).

For making conclusion evaluation sub-skill, the results indicated that the mean score of nativized reading passages (Mean $=3.711, \mathrm{Std}=.835)$ was significantly higher than the mean score of original reading passages (Mean $=2.395$, $\mathrm{Std}=.974) ; \mathrm{t}(37)=11.562, \mathrm{p}<.01$; the standardized effect size index, d, was 1.90 (considerable effect size: (Cohen [41]).

To investigate the significance of the performance difference between the overall students' performance in original and the nativized reading passages Repeated Measures Analysis (i.e., Paired Samples t-test) were conducted. Table (10) illustrates the results of a paired samples t-test for the difference between student's performance in original and the nativized reading passages.

Table 9. Results of A paired samples t-test for the Difference between Student's Performance in Original and the Nativized Reading Passages for the Evaluation Reading Level and its Sub-skills.

\begin{tabular}{|c|c|c|c|c|c|c|c|}
\hline Sub-skills & & Mean & Std Deviation & T-values & df & Sig. & Effect size \\
\hline \multirow{2}{*}{ Offering opinion } & Original & 3.158 & .855 & \multirow{2}{*}{8.055} & \multirow{2}{*}{37} & \multirow{2}{*}{.000} & \multirow[t]{2}{*}{1.32} \\
\hline & Nativized & 4.026 & .434 & & & & \\
\hline \multirow{2}{*}{ Analyzing Information } & Original & 2.790 & .991 & \multirow{2}{*}{11.237} & \multirow{2}{*}{37} & \multirow{2}{*}{.000} & \multirow[t]{2}{*}{1.85} \\
\hline & Nativized & 4.000 & .569 & & & & \\
\hline \multirow{2}{*}{ Evaluating } & Original & 2.500 & 1.007 & \multirow{2}{*}{13.008} & \multirow{2}{*}{37} & \multirow{2}{*}{.000} & \multirow[t]{2}{*}{2.15} \\
\hline & Nativized & 3.790 & .741 & & & & \\
\hline \multirow{2}{*}{ Making a conclusion } & Original & 2.395 & .974 & \multirow{2}{*}{11.562} & \multirow{2}{*}{37} & \multirow{2}{*}{.000} & \multirow[t]{2}{*}{1.90} \\
\hline & Nativized & 3.711 & .835 & & & & \\
\hline \multirow{2}{*}{ Total } & Original & 10.842 & 3.628 & \multirow{2}{*}{16.435} & \multirow{2}{*}{37} & \multirow{2}{*}{.000} & \multirow[t]{2}{*}{2.70} \\
\hline & Nativized & 15.526 & 2.227 & & & & \\
\hline
\end{tabular}


Table 10. Results of A paired samples t-test for the Difference between Students' Performance in Original and the Nativized Reading Passages

\begin{tabular}{|c|c|c|c|c|c|c|c|}
\hline Variable & & Mean & Std Deviation & $\mathrm{T}$ - values & Df & Sig. & \\
\hline \multirow{2}{*}{ Total } & Original & 40.632 & 6.992 & \multirow{2}{*}{23.664} & \multirow{2}{*}{37} & \multirow{2}{*}{.000} & \\
\hline & Nativized & 51.39 & 4.902 & & & & 3.89 \\
\hline
\end{tabular}

As shown in table (10), the results indicated that the mean score of nativized reading passages (Mean $=51.39$, $\mathrm{Std}=4.902$ ) was significantly higher than the mean score of original reading passages $(\mathrm{Mean}=40.632, \mathrm{Std}=6.902) ; \mathrm{t}$ $(37)=23.664, p<.01$; the standardized effect size index, $d$, was 3.89 (huge effect size: (Cohen, [41]).

To sum up, students' performance in nativized reading passages and their sub-skills were significantly higher than their performance in original reading passages and sub-skills.

\section{Discussion}

The current study aimed at exploring the potential effect of cultural clues on EFL undergraduates' literal, inferential, and evaluative comprehension levels. In doing so, seven reading passages were selected from the textbook taught at Al al-bayt university as a compulsory course. These passages were nativized to the Jordanian culture by replacing all words related to cultural concepts, either visible or invisible. The selected participants were first asked to read the original passages and answer some questions that measured their literal, inferential, and evaluative comprehension levels. After two weeks, the same participants were given the nativized versions of the same passages, and also they were asked to answer some questions which measured the same previous levels. The results were put on tables, and each Table represents the results connected to each question of this study.

Concerning the results of the first question, which was related to students' performance in reading the original versions of passages, it was noticed that students' performance was the best in literal comprehension level, followed by inferential and finally evaluative level in which students got the lowest scores. Also, it was noticed that in a literal reading level, the students were best at "Identifying important points" sub-skill. While in inferential comprehension level, the students were the best at "Interpreting important points", and finally, for the evaluative comprehension level, they performed well in the "Offering opinion" sub-skill.

These results can be explained as when students read passages that were irrelevant to their culture might fail to understand or comprehend the whole passage. Consequently, this kind of misunderstanding led to a surface concept about the passage which, in turn, produced students who are incapable of answering questions that need analysis, looking between lines, and making conclusions. Accordingly, students' misunderstanding of the original passages was mirrored on their performance of questions related to the three levels' sub-skills.

Considering the second question's results, which was related to the students' performance in reading the nativized versions of the same passages, it was indicated that students performed positively in literal comprehension level, neutrally in both inferential comprehension level and evaluative level. In details, the students were the best at "Identifying important points" as literal sub-skill, while they performed well in "Gap-filling" as inferential sub-skill, and "Offering opinion" as an evaluative sub-skill was preferable for students.

In contrast, a potential justification for students' positive performance could be attributed to the fact that in the case of nativized versions, students were dealing with culturally familiar passages. They could activate their schema related to the topics of the passages resulting in comprehending the passages successfully. In other words, when the students were familiar with cultural textual and contextual clues that represented different aspects of the Jordanian culture, they would be able to answer comprehension questions with their three levels.

According to the results of the third question, which was related to the differences between the test scores of the original and the nativized reading passages, it was concluded that students' performance in nativized reading passages and its sub-skills were significantly higher than their performance in original reading passages and its sub-skills. The findings are therefore consistent with researchers such as (Sasaki, [29]; Yousef\& Karimi and Janfeshan, [35]; Khataee \& Davoudi, [36]; Alptekin, [23] and Demir [39] who agreed that when students were provided by cultural background related to the topic they are reading this would positively influence their inferential reading comprehension and accordingly improve their language proficiency. Also, the students who read the nativized version of the text would perform better in reading comprehension tests than the students are given the original version.

Based on these results which reflected observed improvements in students' performance in reading the nativized passages, the researcher concluded that these improvements could be attributed to the use of familiar cultural clues which were related to the students' culture, where such cultural clues reflected known aspects which made the passages more straightforward and more acceptable for the students. Henceforth, using familiar cultural clues played a significant role in improving 
students' comprehension with its three levels. This way, the researcher nativized the original passages and tried to make the passages related to the students' culture, where the students felt they were living the same experience since they were familiar with all cultural aspects and clues embedded in the passages.

In this regard, the researcher made some justifications on the benefits of using familiar cultural clues. The substantial primary justification for the improvement of students' comprehension was attributed to the process of nativization, where all the strange cultural clues in the original passages were adapted to be related to the students' Jordanian culture. Another justification that the researcher thought it improved students' comprehension was students' feelings of enjoyment and self-confidence since reading passages related to their culture and reflected aspects that were easily comprehended. Hence, being familiar with the passages' topics provided students with a safe environment that encouraged them to answer the questions of the passages without hesitation. This proves the importance of activating prior knowledge while reading to build up a clear image of the passage topic. Accordingly, students found it very easy to activate prior knowledge or schema when reading the nativized versions.

\section{Conclusions}

Based on the results' discussion, the researcher came up with the following conclusions:

- It is essential to provide students with cultural background knowledge related to the topic they read because cultural familiarity positively affects students' comprehension.

- Text nativization played a significant role in activating students' schema while reading, which helped them have an excellent performance in reading comprehension.

- Literal, inferential, and evaluative comprehension levels were positively affected by cultural familiarity, especially when applying text nativization.

- Nativized passages have improved students' comprehension.

- Nativized passages created a kind of interaction between students and reading passages.

- $\quad$ Nativized passages encouraged students to read more and look for their favorite topics.

- Nativized passages made students self-confident since they have a whole idea about what they were reading.

\section{REFERENCES}

[1] Grabe, W., Stoller, F. L, "Teaching and researching reading," Harlow, UK: Pearson Education, 2002.

[2] Ajideh, P., "Schema Theory-based pre-reading tasks: A neglected essential in the ESL reading class," The Reading Matrix, vol. 3, no. 1, pp. 1-14, 2003.

[3] Cameron, L., "Teaching Languages to Young Learners," Cambridge: Cambridge University Press, 2001.

[4] Wolf, M., "Proust and the Squid: The Story and Science of the Reading Brain," New York: Harper Collins, 2007.

[5] Rose-Smith, M., "Teaching Reading Strategies," State of New South Wales through the NSW Department of Education and Training 2010.

[6] Perfetti, A., Landi, N., Oakhill, J. ,"The Acquisition of Reading Comprehension Skills". In M. J. Snowling and C. Hulme (Eds.), "The Science of Reading: A Handbook, "Oxford: Blackwell. Cain, K., 2005, pp. 227-247.

[7] Rumelhart, D. E., "Schemata: The building blocks of cognition," Theoretical Issues in Reading Comprehension, 1980, 9781315107493-4.

[8] Anderson, R. C., Pearson, P. D., "A schema-theoretic view of reading comprehension," In P. D. Pearson (Ed.), "Handbook of Reading Research", , New York: Longman, 1984, pp. 255-291.

[9] Carrell, P. L, Eisterhold. J. C., "Schema Theory and ESL Reading Pedagogy," TESOL Quarterly, vol. 17, no.4, pp. 553-573, 1983.

[10] Ketchum, E. M.,"The cultural baggage of second language reading: An approach to understanding," Foreign Language Annals, vol.39, pp. 22-42, 2006.

[11] Kim, M. ,"Adult ESL Korean readers' responses to their reading in L1 Korean and L2 English," (Doctoral dissertation).Available from Pro Quest Dissertations and Theses database 2010.

[12] Garner, R., "Metacognition and reading comprehension," Norwood. NJ: Ablex, 1997.

[13] Jalilifar A. R., Assi R. ,"The Role of Cultural Nativization in Comprehension of Short Stories in EFL Reading Contexts," The International Journal of Language Society and Culture, vol. 26, pp. 62-79, 2008.

[14] Barnett, A.," More than Meets the Eye: Foreign Language Reading: Theory and Practice," ERIC Clearinghouse on Languages and Linguistics, Washington, D.C. Englewood Cliffs, N, J: Prentice Hall Regents, 1989.

[15] Clymer, T., "What is reading?: Some current concepts," In H. M. Robinson (Ed.), "Innovation and Change in Reading Instruction: The Sixty-seventh Yearbook of the National Society for the Study of Education," Chicago: The National Society for the Study of Education, 1968, pp. 7 - 29 .

[16] Nassaji, H., "Schema theory and knowledge-based processes in second language reading comprehension: A need for alternative perspectives,".Language learning, vol. 52, no. 2, pp. 439-481, 2002.

[17] Davoudi, M., Ramezani, H., "The Effects of Cultural Familiarity on Reading Comprehension of Iranian EFL Learners," International Journal on Studies in English Language and Literature (IJSELL), vol. 2, no.8, pp. 58-71, 
2014.

[18] Bernhardt, E., "Reading development in a second language," New York: Ablex, 1991.

[19] Erten, İ. H., "Activation of Prior Knowledge," The TESOL Encyclopedia of English Language Teaching, 2018, pp. 1-6.

[20] Hinkel, E.,"Building awareness and practical skills to facilitate cross-cultural communication. Teaching English as a second or foreign language", vol. 3, pp. 443-458, 2001.

[21] Barnett, A., "More than Meets the Eye: Foreign Language Reading: Theory and Practice," ERIC Clearinghouse on Languages and Linguistics, Washington, D.C. Englewood Cliffs, N, J: Prentice Hall Regents, 1989.

[22] Pulido, D., "The effect of cultural familiarity on incidental vocabulary acquisition through reading," The Reading Matrix, an Online International Journal, vol. 4, pp. 20-53, 2004.

[23] Alptekin, J., "Cultural familiarity in inferential and literal comprehension in L2 reading," The System, vol. 34, no. 4, pp. 494-508, 2006.

[24] Ketchum, E. M., "The cultural baggage of second language reading: An approach to understanding," Foreign Language Annals, vol. 39, pp. 22-42, 2006.

[25] Oller, J. W., "Adding abstract to formal and content schemata: Results of recent work in Peircean semiotics," Applied Linguistics, vol.16, pp. 273-306, 1995.

[26] Beck, I. L., McKeown, M. G. "Trends in instructional research in reading: A retrospective," Washington, DC: National Institute of Education, 1982.

[27] Johnson, P., Effects on Reading Comprehension of Language Complexity and Cultural Background of a Text. TESOL Quarterly, vol. 15, no. 2, pp. 169-181, 1981.

[28] Bedir, H., "Cultural significance in foreign language learning and teaching emphasizes reading comprehension through cultural schema," (Unpublished master's thesis). Çukurova University, Adana, 1992.

[29] Sasaki, M., "Effects of cultural schemata on students' test-taking processes for cloze tests: A multiple data sources approach," Language Testing, vol. 17, no. 1, pp. 85-114, 2000.

[30] Chang, Y. L., "The cross-cultural background knowledge in EFL reading comprehension," Chi-Nan Annual Bulletin, vol.
33, pp. 383-393, 2007.

[31] Garth-McCullough, R., Untapped cultural support: "The influence of culturally bound prior knowledge on comprehension performance". Reading Horizons, vol. 49, no. 1, pp. 1-23, 2008.

[32] Dehghan, F., Sadighi, F. , "On the Cultural Schema and Iranian EFL Learners' Reading Performance: A Case of Local and Global Items," Journal of Pan-Pacific Association of Applied Linguistics, vol. 15, no. 2, pp. 97-108, 2011.

[33] Rashidi, N., Soureshjani, K. H. , "Teaching culturally-based texts on Persian English as a foreign language (EFL) learners' motivation and reading performance," Journal of Languages and Culture, vol. 2, no. 8, pp. 141-147, 2011

[34] Maghsoudi, N., "The Impact of Schema Activation on Reading Comprehension of Cultural Texts among Iranian EFL Learners," 2012.

[35] Yousef, H., Karimi, L., Janfeshan, K. , "The relationship between cultural background and reading comprehension," Theory and Practice in Language Studies, vol. 4, no.4, pp. $707,2014$.

[36] Khataee, E. Davoudi, M, The Role of Cultural Schemata in Inferential Reading Comprehension: An Investigation in the Iranian EFL Context. ASEAN Journal of Teaching\& Language in Higher Education, vol.10, no. 2, pp.11-27, 2018.

[37] Sheridan, R., Tanaka,k., Hogg, N., "Foreign Language, Local Culture: How Familiar Contexts Impact Learning and Engagement," The Electronic Journal for English as a Second Language, vol. 23, no.1, 2019.

[38] Razi, S.,"An investigation into the impact of cultural knowledge on reading comprehension," Reading Teacher, 2003, pp.546-556.

[39] Demir, Y., "The Effect OF Background Knowledge and Cultural Nativization On Reading Comprehension and Vocabulary Inference," Journal of Educational and Instructional Studies in The World, vol. 2, no. 4, pp.188-198, 2012.

[40] Cronbach, L. J., "Coefficient alpha and the internal structure of tests," Psychometrika, vol.16, no. 3, pp. 297-334, 1951.

[41] Cohen, J., "Statistical power and analysis for the behavioral sciences," (2nd ed.), Hillsdale, NJ: Lawrence Erlbaum Associates, 1988. 